\title{
INFLUÊNCIA DA DISFUNÇÃO ORAL DO NEONATO A TERMO SOBRE O INÍCIO DA LACTAÇÃO
}

\author{
Influence of oral dysfunction on full-term newborn \\ on the beginning of lactation
}

\author{
Karine Dutra Valério ${ }^{(1)}$, Cláudia Marina Tavares de Araújo ${ }^{(2)}$, Sônia Bechara Coutinho ${ }^{(3)}$
}

\begin{abstract}
RESUMO
Objetivo: verificar a associação entre a disfunção oral e os fatores socioeconômicos, variáveis relacionadas à mãe e ao recém-nascido com o desempenho da mamada, durante as primeiras 48 horas de vida. Métodos: estudo transversal, analítico, realizado em uma maternidade pública do Recife-PE. Foram entrevistadas todas as mães de crianças nascidas a termo entre abril e julho de 2008, perfazendo 588 binômios mãe/recém-nascido. A avaliação do sistema sensório motor oral do neonato e avaliação da mamada foram elaboradas, codificando-se como zero quando o item era "esperado/ normal" e um quando "não esperado/de risco". A soma total dos itens "não esperados/de risco" resultou em um Índice de Disfunção Oral e um Índice de Avaliação da Mamada. Resultados: verificou-se que $57,3 \%$ dos binômios mães/recém-nascidos apresentavam alteração da mamada, 43,9\% apresentavam 1 e/ou 2 alterações e 13,4\% maior número de alterações. A frequência de disfunção oral foi de aproximadamente $30 \%$. Na análise de regressão logística entre as variáveis incluídas, apenas a disfunção oral manteve-se associada significativamente com o insucesso da mamada. Crianças com maior número alterações da função oral apresentaram chance 4 vezes maior de ter alteração da mamada. Conclusões: sendo as disfunções orais uma das causas para o não estabelecimento da lactação, estas devem ser identificadas precocemente, visto que podem ser corrigidas, evitando o desmame. As maternidades devem possuir equipe capacitada no manejo do aleitamento, com um profissional que dê atenção especial às alterações do sistema sensório motor oral.
\end{abstract}

DESCRITORES: Aleitamento Materno; Comportamento de Sucção; Desmame; Lactação; Recém-Nascido

\section{INTRODUÇÃO}

O leite materno é a mais adequada fonte de nutrientes para o recém-nascido e uma rica fonte

(1) Fonoaudióloga autônoma; Mestre em Saúde da Criança e do Adolescente do Programa de Pós-graduação em Saúde da Criança e do Adolescente da Universidade Federal de Pernambuco.

(2) Fonoaudióloga; Professora Adjunta do Departamento de Fonoaudiologia do Centro de Ciências da Saúde da Universidade Federal de Pernambuco, UFPE, Recife, PE; Doutora em Nutrição do Programa de Pós-graduação em Nutrição da Universidade Federal de Pernambuco.

(3) Médica; Professora Associada do Departamento MaternoInfantil da Centro de Ciências da Saúde da Universidade Federal de Pernambuco, UFPE, Recife, PE; Doutora em Nutrição do Programa de Pós-graduação em Nutrição da Universidade Federal de Pernambuco.

Conflito de interesses: inexistente de anticorpos. O aleitamento materno oferece a oportunidade de uma harmoniosa interação mãe/ filho, contribuindo psicologicamente para uma relação saudável, favorecendo o crescimento e o desenvolvimento adequados para a criança e de suas estruturas orais ${ }^{1-4}$.

A sucção no peito é um importante estimulador do crescimento crânio-facial ${ }^{5,6}$, pois durante esse processo, todas as estruturas orais como lábios, língua, bochechas, ossos e músculos da face se desenvolvem e se fortalecem, promovendo a atuação harmônica das funções estomatognáticas ${ }^{7-9}$. Além disso, é a maneira mais indicada e adequada para promover o desenvolvimento motororal e o estabelecimento correto das funções realizadas pelos órgãos fonoarticulatórios ${ }^{9,10}$.

Alguns fatores podem interferir no estabelecimento da lactação durante as primeiras $48 / 72$ 
horas de vida do neonato, favorecendo o desmame precoce. Estes fatores podem estar relacionados à mãe, ao binômio mãe-bebê e especificamente, ao recém-nascido ${ }^{10-13}$.

Os primeiros dias de vida correspondem a um momento importante para a amamentação, porque o recém-nascido pode apresentar desordens no padrão de sucção (disfunção oral), refletindo no desenvolvimento motor-oral ${ }^{11}$, prejudicando assim, o desempenho da lactação ${ }^{12}$.

Sanches ${ }^{14}$ em um estudo do tipo transversal, na cidade de Santos em 1997, observou a mamada de 409 binômios mães/recém-nascidos, em um Hospital Amigo da Criança, identificando 13\% de recém-nascidos com mamada insatisfatória que apresentaram disfunção oral, a despeito de tratarse de uma população de crianças com condições orgânicas, psíquicas e funcionais favoráveis para a amamentação. Outro estudo ${ }^{15}$ analítico, com corte transversal, realizado na cidade de Maceió, em uma maternidade pública estadual, identificou durante a avaliação da mamada, os piores resultados como sendo relativos à adequação da sucção dos bebês, uma vez que $44 \%$ dos binômios avaliados apresentaram alteração neste aspecto.

Os neonatos com disfunções orais requerem muita habilidade na aprendizagem para ordenhar o peito de suas mães, sendo necessário interceder precocemente mediante as primeiras dificuldades durante o estabelecimento da lactação mãe/recémnascido ${ }^{11}$. Assim, em casos de disfunções orais do neonato um profissional especializado deve atuar de imediato, visando ${ }^{15}$ o reequilíbrio das funções do sistema estomatognático, diagnosticando e intervindo nas desordens funcionais desse sistema, para facilitar um adequado funcionamento oral ${ }^{11}$, principalmente levando-se em conta que tal dificuldade (disfunção oral), quando não abordada corretamente, pode implicar no desmame precoce ${ }^{16}$.

Com base nesse fato, o objetivo desse estudo foi verificar a associação entre a disfunção oral, fatores socioeconômicos, variáveis relacionadas à mãe e ao recém-nascido com o desempenho da mamada durante as primeiras 48 horas do neonato.

\section{MÉTODOS}

Estudo do tipo transversal descritivo, com componente analítico, realizado na Maternidade Professor Bandeira Filho, pertencente ao Distrito Sanitário V, da cidade de Recife, estado de Pernambuco. A escolha desta unidade se deu pelo fato de a maternidade ser de baixa complexidade, oferecer assistência integral à saúde da mulher e da criança, com atendimento básico e proposta de acompanhamento pré, peri e pós-natal. Possui 44 leitos e realiza cerca de 300 partos por mês, dos quais $27 \%$ são cirúrgicos.

A maternidade também dispõe de equipe especializada para oferecer apoio às mães com palestras sobre aleitamento materno no pré-natal, durante internamento da díade mãe-bebê e por ocasião do primeiro retorno após a alta, além de assistência no manejo do aleitamento. Adquiriu o título de Hospital Amigo da Criança em dezembro de 2002.

Participaram da pesquisa todas as mães e neonatos a termo saudáveis, que nasceram na maternidade no período de abril a julho de 2008, perfazendo um total de 588 binômios mãe/recémnascido. Foram excluídos os recém-nascidos gêmeos, pré-termos (<37 semanas) ou póstermos ( $\geq 42$ semanas), com baixo peso ao nascer $(<2500 \mathrm{~g})$, crianças que necessitaram de internação na unidade neonatal ou apresentaram doenças neonatais, más formações congênitas em órgãos fonoarticulatórios e / ou cujas mães estivessem impossibilitadas de amamentar por doenças ou uso de medicações que contra-indicassem esta prática.

\section{Variáveis do Estudo}

- Idade materna: em anos.

- Número de filhos: quantos filhos vivos possui.

- Experiência anterior com amamentação: se a mãe já amamentou outro filho.

- Escolaridade materna: número de anos que a mãe frequentou a escola.

- Renda familiar: quantos salários mínimos a família recebe por mês.

- Tipo de parto: transpelviano ou cirúrgico.

- Peso do neonato: igual ou superior a 2500 gramas.

- Idade gestacional ao nascimento: entre 37 e 41 semanas e seis dias, avaliada por meio do método de Capurro ${ }^{17}$ ou data da última menstruação (DUM).

- Disfunção oral: dificuldade durante a amamentação causada por alteração na cavidade oral do recém-nascido, ou seja, em seus músculos e/ou estruturas do sistema estomatognático, tais como movimentos mandibulares restritos, língua posteriorizada, ausência de vedameto labial no peito, ritmo inadequado de sucção, ausência ou deficiência do reflexo de procura ${ }^{16}$.

- As variáveis relacionadas à avaliação do sistema sensório motor oral e à observação da mamada serão descritas abaixo.

Os recém-nascidos foram selecionados através de consulta prévia do registro de nascimento realizada diariamente no centro obstétrico. Ao serem localizadas as mães e seus filhos nas enfermarias, foi realizado o convite para a participação no estudo, 
com explicação verbal detalhada deste. A partir do interesse da mãe, foi entregue o termo de consentimento livre e esclarecido, para que ela pudesse ler e assinar, ficando uma cópia com a participante e outra com a pesquisadora responsável. Posteriormente, foi aplicado o questionário à genitora, contendo dados socioeconômicos e demográficos da família, relacionados ao neonato (dados retirados do prontuário) e ao estabelecimento da lactação. Após preenchimento do questionário, deu-se início a avaliação do sistema sensório motor oral, seguida da observação da mamada. Todos os procedimentos de coleta foram realizados pela pesquisadora responsável.

\section{Avaliação do Sistema Sensório Motor Oral}

Para avaliação do sistema sensório motor oral foi elaborada pelas autoras uma escala baseada nos estudos desenvolvidos por Neiva e Leone ${ }^{5,18}$, Sanches ${ }^{16}$ e Castro ${ }^{6}$ diferenciando o normal/esperado dos fatores de risco/não esperados. O recémnascido foi examinado no alojamento conjunto, entre as primeiras 12 e 24 horas de vida, em estado de alerta, sendo posicionado no colo da examinadora, preferencialmente apoiado no seu braço esquerdo, para a observação das estruturas orais (lábios, língua, bochechas), ainda nesta postura, foi introduzida na boca do recém-nascido a falange distal enluvada do dedo mínimo direito da examinadora, para testar os reflexos orais e movimentação de língua, bochechas e mandíbula.

Como padrão para definir o que era esperado/ normal em cada aspecto avaliado, foram adotados os seguintes parâmetros para cada item:

1. Reflexo de procura: resposta de busca à mama ou ao dedo da avaliadora voltando a cabeça em direção ao estímulo, com boa amplitude de abertura de boca e língua em assoalho da cavidade oral ${ }^{7-9,16}$

2. Reflexo de sucção: resposta ao sugar mediante o toque no ápice da língua e papila palatina, observada por movimentos ondulatórios da língua, de fora para dentro, com manutenção de sua anteriorização ${ }^{8,9,16}$.

3. Reflexo de mordida: movimento de trancamento de gengivas, após estímulo tátil do dedo da examinadora ou do próprio mamilo materno 16.

4. Reflexo de gag: similar ao de vômito, diferenciando-se deste pela menor extensão da musculatura de faringe, laringe e língua, sendo sua resposta por toque a partir do segundo terço da língua ${ }^{8}$.

5. Reflexo de deglutição: ausência de engasgos, tosse, regurgitação ou movimento durante a tentativa de deglutição ${ }^{16}$.
6. Ritmo de sucção: rápido e depois estável, ou seja, movimentos rápidos mandibulares, caracterizados por grupos de sucção, com padrão irregular, para a descida do leite, porém com modificação posterior desse padrão, após a extração do leite pelo recém-nascido, tornandose estável, regular e harmônico ${ }^{7,16}$.

7. Postura de lábios: ambos totalmente evertidos ou lábio inferior com maior eversão ${ }^{7,16}$.

8. Postura de língua: anterior, com a ponta ultrapassando o bordo gengival inferior durante a ordenha ou sucção não-nutritiva ${ }^{7,16}$.

9. Canolamento de língua: língua envolvendo a mama ou dedo da examinadora inferiormente, em forma de cânula ${ }^{7,16}$.

10. Peristaltismo de língua: movimentos de deslocamento ântero-posterior, com a propulsão do leite ${ }^{7,16}$.

11. Movimentos de bochechas: não visualização da participação do músculo bucinador durante a ordenha ou sucção não-nutritiva ${ }^{16}$.

12. Movimentos mandibulares: coordenados e suaves, observando sincronia e ritmo entre a elevação/anteriorização e abaixamento/posteriorização. Esses movimentos são realizados de modo conjugado com o ritmo da sucção, verticais e mínimos durante a mamada ou sucção não-nutritiva ${ }^{7,16}$.

Quando o item do desenvolvimento observado era o "esperado/normal" codificava-se como zero (0) e, quando "não esperado/de risco" recebia o código um (1) ${ }^{6}$. A soma total dos itens "não esperado/de risco" resultou em um Índice de Disfunção Oral que poderia variar de 0 a 12 ponto. Registrou-se neste estudo uma pontuação máxima para este índice de 10 pontos, caracterizando a situação mais desfavorável.

\section{Avaliação da Mamada}

A mamada da criança foi avaliada utilizando-se o formulário de observação da mamada do curso do Unicef/OMS "Manejo e promoção do aleitamento materno num hospital amigo da criança, curso de 18 horas para equipes de maternidades" 19 adaptado para o estudo. Para tanto, foi solicitado à mãe que colocasse o recém-nascido no peito, ainda em estado de alerta, para realizar a sucção nutritiva através do aleitamento materno, e a avaliadora observou os aspectos relativos ao tipo de mamilo e condições da mama da mãe, postura global da criança no peito, estabelecimento de laços afetivos, reflexos orais, vedamento labial, pega no peito materno, postura de língua, movimentos de bochechas e mandíbula, coordenação entre sucção/ deglutição/respiração e se a mãe possuía dificuldade no aleitamento materno. 
Como padrão para definir o que era esperado/ normal em cada aspecto avaliado, foram adotados os seguintes parâmetros para cada item:

1. Posição corporal: postura materna confortável, cabeça e queixo do bebê tocando o peito, nádegas apoiadas ${ }^{19}$.

2. Respostas do bebê: procura o peito quando sente fome, gira, busca e explora o peito com a língua, fica calmo e alerta, mantendo a pega da aréola. Na mãe são observados sinais de ejeção de leite (vazamento, fisgadas e cólicas uterinas) ${ }^{19}$.

3. Estabelecimento de laços: mãe segura o filho com firmeza, mantém contato visual. Há grande quantidade de toques ${ }^{19}$.

4. Anatomia do mamilo: formato normal e protruso ${ }^{19}$.

5. Condições das mamas: macias, cheias e arredondadas antes da mamada, tecido com aparência saudável ${ }^{19}$.

6. Coordenação sucção/deglutição/respiração: sucção lenta e vigorosa com períodos de pausa, sendo possível ver e/ou ouvir a deglutição, observando um ritmo harmônico e sincronizado entre sugar, deglutir e respirar, sem soltar a mama e sem dificuldades em retomar a ordenha para continuar a mamada $7,16,19$.

Quando o item da avaliação da mamada era o "esperado/normal" codificava-se como zero (0) e, quando "não esperado/de risco" recebia o código um (1). A soma total dos itens "não esperado/de risco" resultou em um Índice de Avaliação da Mamada que poderia variar de 0 a 6 pontos. A pontuação máxima observada para este índice foi de 5 pontos, caracterizando a situação mais desfavorável.

Os índices de disfunção oral e de avaliação da mamada foram elaborados utilizando-se o programa Statistical Package for the Social Science (SPSS), versão 12. Esses índices foram categorizados, tomando-se por base as distribuições de frequências de cada um, e subdividiram-se as categorias de disfunção oral em: sem alteração (0), com 1 a 2 e de 3 a 10 alterações. As categorias da avaliação da mamada foram subdivididas em: sem alteração (0), 1 a 2 e de 3 a 5 alterações. Na Figura 1 são apresentados os critérios empregados na classificação desses índices.

\begin{tabular}{|c|c|c|}
\hline Índices & $\begin{array}{c}\text { №. de comportamentos } \\
\text { investigados }\end{array}$ & Classificação dos índices \\
\hline Disfunção oral & 12 & Sem alteração 0 1 a 2 alterações 3 a 10 alterações \\
\hline $\begin{array}{l}\text { Avaliação da } \\
\text { mamada }\end{array}$ & 06 & 1 a 2 alterações \\
\hline
\end{tabular}

Figura 1 - Classificação dos índices de disfunção oral e de avaliação da mamada. Recife, 2008

Antecedeu à coleta, estudo piloto na referida maternidade com 23 duplas mãe/filho, com o objetivo de testar o instrumento de coleta (questionário) para realizar os ajustes necessários.

O presente estudo foi aprovado pelo Comitê de Ética em Pesquisa em Seres Humanos do Hospital Agamenon Magalhães/PE com o protocolo de número 56/2008, conforme normas para pesquisa envolvendo seres humanos através da Resolução 196/96.

Os dados obtidos foram codificados e processados em dupla entrada para validação, através do software Epi Info versão 6.04. As análises estatísticas foram realizadas com o pacote estatístico SPSS, versão 12. Inicialmente realizou-se análise univariada entre as variáveis independentes e a avaliação da mamada (variável dependente). Para comparação das proporções foi realizado o teste do qui-quadrado, tomando-se o valor de $p \leq 0,05$, como estatisticamente significante.

Realizou-se análise de regressão logística com a finalidade de identificar a contribuição independente das variáveis estudadas em relação à avaliação da mamada. As variáveis com valor de $p \leq 0,20$ na análise univariada foram selecionadas para serem submetidas à análise multivariada, utilizando-se o método enter. A variável avaliação da mamada foi categorizada em dois grupos: sem alterações (0) e com 1 a 5 alterações.

\section{RESULTADOS}

As mães participantes tinham entre 13 e 43 anos, com média de 24 anos $(\mathrm{DP}= \pm 6,0)$, sendo que um quarto delas era adolescente, possuindo em média dois filhos. Aproximadamente a metade das mães avaliadas não tinha experiência prévia com amamentação, pelo fato de se ter um grande número de primíparas no estudo (47,1\%). Contudo, para a análise desta variável, ao serem excluídas as primíparas (277/588 mães), verificou-se que a grande maioria das multíparas tinha experiência anterior em amamentar. Entre as mulheres estudadas, $56,3 \%$ tinha até oito anos de estudo, sendo 
uma população de baixo poder aquisitivo, com metade pertencente a famílias renda mensal de até um salário mínimo.

Dentre os neonatos, três quartos nasceram de parto transpelviano, $52 \%$ eram do sexo masculino e apenas 4,6\% (27/588) das crianças não estavam em aleitamento materno exclusivo. O peso dos recém-nascidos variou de $2500 \mathrm{~g}$ a $4815 \mathrm{~g}$, com 25,3\% apresentando peso insuficiente $e$
$17,4 \%$ com idade gestacional entre 37 e 38 semanas.

A avaliação das alterações relacionadas ao sistema sensório motor oral nas primeiras 48 horas de vida são observadas na Tabela 1. Nesta tabela, é possível observar alterações em praticamente todos os aspectos avaliados, sendo as mais evidentes o reflexo de procura $(15,3 \%)$, reflexo de sucção (11,2\%) e ritmo de sucção (17,3\%), seguindo a sequência da avaliação.

Tabela 1 - Avaliação do sistema sensório motor oral nas primeiras 48 horas de vida. Recife, 2008

\begin{tabular}{|c|c|c|}
\hline \multirow[t]{2}{*}{ Variáveis } & \multicolumn{2}{|c|}{ Total $(\mathrm{N}=588)$} \\
\hline & $\mathbf{N}$ & $\%$ \\
\hline \multicolumn{3}{|c|}{ Reflexo de procura } \\
\hline normal & 498 & 84,7 \\
\hline alterado & 90 & 15,3 \\
\hline \multicolumn{3}{|c|}{ Reflexo de sucção } \\
\hline normal & 522 & 88,8 \\
\hline alterado & 66 & 11,2 \\
\hline \multicolumn{3}{|c|}{ Reflexo de mordida } \\
\hline normal & 575 & 97,8 \\
\hline alterado & 13 & 2,2 \\
\hline \multicolumn{3}{|c|}{ Reflexo de gag } \\
\hline normal & 584 & 99,3 \\
\hline alterado & 4 & 0,7 \\
\hline \multicolumn{3}{|c|}{ Reflexo de deglutição } \\
\hline normal & 588 & 100,0 \\
\hline alterado & 0 & 0,0 \\
\hline \multicolumn{3}{|c|}{ Ritmo de sucção } \\
\hline normal & 486 & 82,7 \\
\hline alterado & 102 & 17,3 \\
\hline \multicolumn{3}{|c|}{ Postura de lábios } \\
\hline normal & 562 & 95,6 \\
\hline alterado & 26 & 4,4 \\
\hline \multicolumn{3}{|c|}{ Postura de língua } \\
\hline normal & 568 & 96,6 \\
\hline alterado & 20 & 3,4 \\
\hline \multicolumn{3}{|c|}{ Canolamento de língua } \\
\hline normal & 566 & 96,3 \\
\hline alterado & 22 & 3,7 \\
\hline \multicolumn{3}{|c|}{ Peristaltismo de língua } \\
\hline normal & 550 & 93,5 \\
\hline alterado & 38 & 6,5 \\
\hline \multicolumn{3}{|c|}{ Movimentos de bochechas } \\
\hline normal & 569 & 96,8 \\
\hline alterado & 19 & 3,2 \\
\hline \multicolumn{3}{|c|}{ Movimentos mandibulares } \\
\hline normal & 560 & 95,2 \\
\hline alterado & 28 & 4,8 \\
\hline
\end{tabular}


Tabela 2 - Avaliação da mamada nas primeiras 48 horas de vida. Recife, 2008*

\begin{tabular}{|c|c|c|}
\hline \multirow[t]{2}{*}{ Variáveis } & \multicolumn{2}{|c|}{ Total $(\mathrm{N}=588)$} \\
\hline & $\mathbf{N}$ & $\%$ \\
\hline \multicolumn{3}{|c|}{ Posição corporal } \\
\hline normal & 473 & 80,4 \\
\hline alterado & 115 & 19,6 \\
\hline \multicolumn{3}{|c|}{ Respostas da criança (pega) } \\
\hline normal & 350 & 59,5 \\
\hline alterado & 238 & 40,5 \\
\hline \multicolumn{3}{|c|}{ Estabelecimentos de laços afetivos } \\
\hline normal & 526 & 89,5 \\
\hline alterado & 62 & 10,5 \\
\hline \multicolumn{3}{|l|}{ Anatomia } \\
\hline \multicolumn{3}{|l|}{ mamilo } \\
\hline normal & 463 & 78,7 \\
\hline alterado & 125 & 21,3 \\
\hline \multicolumn{3}{|c|}{ condições da mama } \\
\hline normal & 537 & 91,3 \\
\hline alterado & 51 & 8,7 \\
\hline \multicolumn{3}{|c|}{ Coordenação sucção/ deglutição/ respiração } \\
\hline normal & 587 & 99,8 \\
\hline alterado & 1 & 0,2 \\
\hline
\end{tabular}

*Fonte: Unicef/OMS. Manejo e promoção do aleitamento materno num Hospital Amigo da Criança; um curso de 18 horas para equipes de maternidades. Brasília; 1993. Formulário de avaliação da mamada adaptado.

Na Tabela 2 foram verificados seis itens para a avaliação da mamada nas primeiras 48 horas de vida do recém-nascido, na qual se observaram comportamentos alterados com maior frequência no que se referem à posição corporal da mãe e do bebê (19,6\%), respostas do neonato (pega) $(40,5 \%)$ e anatomia do mamilo (21,3\%). Apenas uma criança $(0,2 \%)$ apresentou alteração na coordenação entre as funções sucção/deglutição/respiração, o que já era de se esperar para uma população de recémnascidos a termo e saudáveis.

A avaliação da mamada segundo as variáveis maternas, do neonato e da disfunção oral, são observadas na Tabela 3. Verifica-se que $42,7 \%(251 / 588)$ das duplas mães/recém-nascidos não apresentaram alteração da mamada, 43,9\% (258/588) com pequenas alterações (de 1 a 2), e 13,4\% (79/588) com maior número de alterações (3 a 10), dados não apresentados em tabela. As primíparas foram as que tiveram maiores percentuais de alteração na avaliação da mamada (dado estatisticamente significante). Não houve diferença entre os grupos avaliados nos aspectos relativos à idade materna, experiência anterior com amamentação, escolaridade, renda familiar e tipo de parto, assim como as características do recém-nascido (peso e idade gestacional).

Por outro lado, a frequência de disfunção oral na população estudada foi de aproximadamente $30,0 \%$, sendo $11,6 \%$ com maior número de alterações e, $17,9 \%$ com pequenas alterações. Ao ser verificada a influência da disfunção oral no desempenho da mamada, constata-se que quanto maior o número de alterações na disfunção oral, maior o percentual de alterações na avaliação da mamada, estabelecendo uma relação diretamente proporcional $(p<0,001)$.

A Tabela 4 apresenta a razão dos produtos cruzados (OR - odds ratio) ajustados das variáveis incluídas na regressão logística (idade materna, número de filhos e disfunção oral). Apenas a disfunção oral manteve associação significante com o desfecho após o ajuste das variáveis. A ocorrência de disfunção oral esteve associada 
Tabela 3 - Avaliação da mamada segundo as variáveis maternas, do neonato e da disfunção oral. Recife, 2008

\begin{tabular}{|c|c|c|c|c|c|c|c|c|c|}
\hline \multirow{3}{*}{ VARIÁVEIS } & \multicolumn{4}{|c|}{ TOTAL } & \multicolumn{4}{|c|}{ AVALIAÇÃO DA MAMADA } & \multirow{3}{*}{$\mathbf{p}$} \\
\hline & \multicolumn{2}{|c|}{$(\mathrm{N}=588)$} & \multicolumn{2}{|c|}{$\begin{array}{c}\text { SEM } \\
\text { ALTERAÇÕES } \\
(0)(n=251)\end{array}$} & \multicolumn{2}{|c|}{$\begin{array}{c}\text { DE 1 A 2 } \\
\text { ALTERAÇÕES } \\
(n=258)\end{array}$} & \multicolumn{2}{|c|}{$\begin{array}{c}\text { DE } 3 \text { A } 5 \\
\text { ALTERAÇÕES } \\
(n=79)\end{array}$} & \\
\hline & $\mathbf{N}$ & $\%$ & $\mathbf{n}$ & $\%$ & $\mathbf{n}$ & $\%$ & $\mathbf{n}$ & $\%$ & \\
\hline \multicolumn{10}{|l|}{ Idade materna } \\
\hline$<20$ anos & 151 & 25,7 & 54 & 35,8 & 75 & 49,6 & 22 & 14,6 & \\
\hline 20 e mais anos & 437 & 74,3 & 197 & 45,1 & 183 & 41,9 & 57 & 13,0 & 0,134 \\
\hline \multicolumn{10}{|l|}{ Número de filhos } \\
\hline 1 & 277 & 47,1 & 102 & 36,8 & 141 & 50,9 & 34 & 12,3 & \\
\hline 2 ou mais filhos & 311 & 52,9 & 149 & 47,9 & 117 & 37,6 & 45 & 14,5 & 0,005 \\
\hline \multicolumn{10}{|l|}{$\begin{array}{l}\text { Experiência anterior } \\
\text { com amamentação* }\end{array}$} \\
\hline Não & 24 & 7,7 & 11 & 45,8 & 10 & 41,7 & 3 & 12,5 & \\
\hline Sim & 287 & 92,3 & 137 & 47,7 & 108 & 37,6 & 42 & 14,7 & 0,913 \\
\hline \multicolumn{10}{|l|}{$\begin{array}{l}\text { Escolaridade } \\
\text { materna }\end{array}$} \\
\hline Até 4 anos & 99 & 16,8 & 41 & 41,4 & 43 & 43,4 & 15 & 15,2 & \\
\hline De 5 a 8 anos & 232 & 39,5 & 97 & 41,8 & 101 & 43,5 & 34 & 14,7 & \\
\hline De 9 a 16 anos & 257 & 43,7 & 113 & 44,0 & 114 & 44,3 & 30 & 11,7 & 0,866 \\
\hline \multicolumn{10}{|l|}{ Renda familiar } \\
\hline$<0.5$ salário & 118 & 20,1 & 51 & 43,2 & 50 & 42,4 & 17 & 14,4 & \\
\hline 0.5 - 1 salário & 177 & 30,1 & 75 & 42,4 & 74 & 41,8 & 28 & 15,8 & \\
\hline > 1 salário & 293 & 49,8 & 125 & 42,7 & 134 & 45,7 & 34 & 11,6 & 0,729 \\
\hline \multicolumn{10}{|l|}{ Tipo de parto } \\
\hline Cirúrgico & 158 & 26,9 & 63 & 40,0 & 72 & 46,6 & 79 & 13,4 & \\
\hline Transpelviano & 430 & 73,1 & 188 & 43,7 & 186 & 42,0 & 23 & 14,3 & 0,689 \\
\hline \multicolumn{10}{|l|}{ Peso do neonato } \\
\hline $2500 g-2999 g$ & 149 & 25,3 & 67 & 45,0 & 66 & 44,3 & 16 & 10,7 & \\
\hline $3000 g-4815 g$ & 439 & 74,7 & 184 & 41,9 & 192 & 43,7 & 63 & 14,4 & 0,514 \\
\hline \multicolumn{10}{|l|}{ Idade gestacional ${ }^{\star *}$} \\
\hline $37.0-38.0$ semanas & 89 & 17,4 & 36 & 40,4 & 39 & 43,8 & 14 & 15,7 & \\
\hline $38.1-41.6$ semanas & 423 & 82,6 & 178 & 42,0 & 191 & 45,2 & 54 & 12,8 & 0,755 \\
\hline \multicolumn{10}{|l|}{ Disfunção oral } \\
\hline De 3 a 10 alterações & 68 & 11,6 & 12 & 17,7 & 36 & 52,9 & 20 & 29,4 & \\
\hline De 1 a 2 alterações & 105 & 17,9 & 31 & 29,5 & 57 & 54,3 & 17 & 16,2 & \\
\hline Sem alterações (0) & 415 & 70,5 & 208 & 50,1 & 165 & 39,8 & 42 & 10,1 & $<0,001$ \\
\hline
\end{tabular}

significantemente com o insucesso da mamada. Crianças com 3 a 10 alterações da função oral apresentaram uma chance 4 vezes maior de terem alteração da mamada quando comparadas com o grupo que não apresentava disfunção oral.

\section{DISCUSSÃO}

O início da amamentação é um momento muito importante para o fortalecimento do vínculo afetivo tanto para a mãe quanto para o filho. O seu estabelecimento acontece de forma dinâmica, envolvendo diferentes fatores. Assim, algumas alterações encontradas podem ser transitórias, devendo, no entanto, serem valorizadas, visto que sua persistência repercute negativamente na lactação. Por esta razão, é importante sanar essas dificuldades iniciais antes mesmo da alta hospitalar ${ }^{16}$.

Neste estudo, dentre as alterações mais frequentes do sistema sensório motor oral 
Tabela 4 - Análise de regressão logística das variáveis associadas à avaliação da mamada. Recife, 2008

\begin{tabular}{|c|c|c|c|c|c|}
\hline VARIÁVEIS & $\begin{array}{l}\text { OR* não } \\
\text { ajustado }\end{array}$ & $\mathbf{p}$ & $\begin{array}{c}\text { OR* }^{*} \\
\text { Ajustado }\end{array}$ & $\begin{array}{c}\text { Intervalo de } \\
\text { Confiança } 95 \%\end{array}$ & $\mathbf{P}$ \\
\hline \multicolumn{6}{|c|}{ Idade materna (anos) } \\
\hline$<20$ & 1,47 & & 1,11 & {$[0,71 ; 1,73]$} & \\
\hline 20 e mais & 1,00 & 0,047 & 1,00 & & 0,64 \\
\hline \multicolumn{6}{|c|}{ Número de filhos } \\
\hline 1 & 1,58 & & 1,37 & {$[0,94 ; 2,00]$} & \\
\hline 2 ou mais & 1,00 & 0,007 & 1,00 & & 0,10 \\
\hline \multicolumn{6}{|c|}{ Disfunção oral } \\
\hline $3-10$ & 4,69 & & 4,32 & {$[2,23 ; 8,34]$} & \\
\hline $1-2$ & 2,40 & & 2,37 & {$[1,49 ; 3,76]$} & \\
\hline 0 & 1,00 & $<0,001$ & 1,00 & & $<0,001$ \\
\hline
\end{tabular}

* Odds ratio

Regressão logística: nível de significância $p \leq 0,20$

encontradas, destacaram-se o reflexo de procura, reflexo de sucção, e ritmo de sucção. Recémnascidos saudáveis e sem intercorrências que interfiram na amamentação, ocasionalmente apresentam movimentos orais atípicos (disfunções orais) durante a mamada. Estes movimentos podem causar dificuldades na lactação decorrentes de alterações transitórias do próprio funcionamento oral, ou mesmo, de algumas características individuais anatômicas que dificultam o encaixe adequado entre a boca do neonato e a mama de sua mãe ${ }^{14}$.

Um dos sinais desfavoráveis à pega do recémnascido ocorre quando o reflexo de procura está alterado, ou seja, diante da mama, o bebê abre pouco a boca e o lábio inferior everte, o que promove dificuldade na criança em abocanhar a aréola ${ }^{20,21}$. A alteração na resposta ao reflexo de procura não deve passar despercebida, pois, se mantida, pode acarretar uma baixa produção de leite e rejeição do peito pelo bebê ${ }^{15,22}$. Neste estudo $15,3 \%$ das crianças apresentavam debilidade no desempenho desse reflexo.

Outro aspecto associado com a alteração de pega do neonato é o reflexo de sucção e seu ritmo, sendo o ritmo um dos fatores mais frequentemente relacionados às modificações no padrão de ordenha dos recém-nascidos ${ }^{11}$. Ao agrupar as disfunções do reflexo e ritmo de sucção, constatou-se que apenas um terço da população apresentou um padrão alterado, provavelmente, pelo fato de a população ser constituída por crianças nascidas a termo, e em maternidade que desenvolve atividades de apoio e incentivo ao aleitamento materno.

Em um estudo semelhante a este, realizado com 100 binômios mãe/recém-nascidos a termo saudáveis, em uma maternidade pública estadual de alto risco na cidade de Maceió, observou-se que pouco menos da metade da amostra apresentou padrões inadequados de sucção ${ }^{15}$. Esta divergência de valores, provavelmente, ocorreu devido à diferença do tipo de demanda recebida e atenção oferecida em uma maternidade de alta complexidade.

Assim como na população estudada, a literatura também refere que grande parte dos recémnascidos apresenta condições adequadas quanto ao funcionamento do sistema sensório motor oral; contudo, mesmo com um índice baixo de disfunção oral, ressalta a importância de estar atento à essas alterações, visto que, quando presentes, podem levar ao desmame precoce ${ }^{16,20,23}$.

As alterações do sistema motor oral do neonato também podem repercutir na pega, constituindo importante causa para as rachaduras e fissuras mamilares ${ }^{10,12}$, fazendo com que a mãe vivencie experiências negativas, como a dor e passe a demonstrar menor interesse e pré-disposição para amamentar seus filhos ${ }^{1,13,14,24}$. Em um estudo transversal, a incidência de queixas das mães de dor ou esfolamento mamário decorrentes de má pega durante a mamada ocorreu ainda no alojamento conjunto, antes do término das primeiras 48 horas após o parto, em quase metade da população ${ }^{16}$. Por outro lado, neste estudo, apenas $8 \%$ das mães referiram dor durante a amamentação. É provável que essa diferença tenha ocorrido pelo fato de esse aspecto ser subjetivo, podendo estar sujeito à experiência dolorosa individual de cada mãe, além de a maternidade oferecer apoio para a ordenha do leite materno, soma-se a estes fatores a permissão 
de se ter uma acompanhante 24 horas, a disponibilidade com equipe especializada para ajudar às mães no manejo da lactação.

As queixas das mães com relação à amamentação, muitas vezes são negligenciadas pelos profissionais assistentes. Entretanto, esse estudo concorda com outros autores ${ }^{25,26}$, quando alerta para a necessidade em estar atento à queixa inicial das mães com dificuldades para amamentar, pois, nestes casos, há maior risco de desmame precoce.

O manejo do aleitamento materno vem sendo estudado cada vez mais devido a sua importância para o bom estabelecimento da lactação. Mesmo havendo consciência de que se trata de um processo dinâmico, com variações a partir de aspectos inerentes a diferentes fatores, que envolvem tanto mãe como filho, deve ser considerado pelos atores envolvidos, principalmente pelos profissionais que atuam na maternidade ${ }^{12,13}$.

Para um bom desempenho da mamada é importante que se realize a sua avaliação por profissionais treinados, observando detalhadamente os fatores relacionados ao manejo do aleitamento materno. Vários autores ressaltam que o posicionamento da mãe e do filho é de fundamental importância para o estabelecimento da lactação ${ }^{11,15,21}$. Quando mãe e/ou recém-nascido estão mal posicionados, facilita a má pega ${ }^{12,20}$, interferindo na dinâmica de sucção com consequente baixa produção de leite ${ }^{11,21}$. Marques e Melo ${ }^{15}$ identificaram que um terço da população do seu estudo apresentou dificuldade em relação à posição corporal durante a mamada, maior porcentagem que a observada no presente estudo, provavelmente porque a maioria da população foi constituída de multíparas.

No momento da avaliação da mamada, mesmo a sucção sendo um ato reflexo, a ordenha não o é, o que exige do neonato aprender a retirar o leite, adaptando suas condições anatômicas orais para o encaixe na mama de sua mãe. Porém, nem sempre isto acontece, podendo haver algumas dificuldades durante o processo ${ }^{14}$. As más formações dos mamilos (planos, invertidos, pseudo-invertidos), mamilo pouco retrátil ou inelástico também podem ocasionar dificuldades durante a ordenha ou a sucção da criança, assim como mamas muito volumosas ou ingurgitadas geram dificuldades 10,11,15. Neste estudo, foi observada alteração da pega da criança em quase metade da população, corroborando os achados de Sanches ${ }^{16}$; entretanto, apenas um quinto dessas foi referente à posição corporal da díade mãe/recém-nascido ou na anatomia dos mamilos, podendo sugerir que as demais alterações, na sua maior parte, estiveram relacionadas às disfunções orais do neonato.
Nesta pesquisa utilizou-se como já referido anteriormente, o protocolo da Unicef/OMS ${ }^{19}$ para observação do manejo do aleitamento materno. Entretanto, deve-se inferir que tal formulário, embora amplamente utilizado na prática clínica, não foi desenhado como instrumento de pesquisa. Contudo, além do atual trabalho, outros também já utilizaram este formulário em seus estudos ${ }^{15,16}$, visto que este instrumento além de se adequar à avaliação clínica, também permite a observação da relação mãe/neonato durante o aleitamento materno. Ressalta-se também que existem as adaptações à vida extra-uterina do recém-nascido e que muitas das alterações encontradas podem ser transitórias, mas as que persistirem necessitam ser corrigidas o mais precocemente possível ${ }^{1}$.

Algumas pesquisas consideram que mães adolescentes frequentemente alcançam um menor índice de aleitamento, apresentando um risco 2,2 vezes maior de desmamarem precocemente seus filhos, provavelmente porque essas aliam muitas vezes insegurança e falta de confiança em si mesmas, além de imaturidade e problemas com auto-imagem, que dificultam ainda mais o estabelecimento da lactação 1,9,23,27-29. No entanto, há controvérsias visto que outros autores divergem, quando registram em seus estudos que mães adolescentes iniciam mais precocemente a amamentação ${ }^{29,30}$, ou ainda e, como registrado neste estudo, que a idade materna não influenciou o desempenho satisfatório da mamada ${ }^{22,26}$.

Há um consenso entre estudiosos ao relatarem que primíparas têm maior chance de apresentar mamada insatisfatória, pois a falta de experiência é considerada fator de risco para o desmame precoce, afinal, mães que tiveram experiência prévia positiva, provavelmente terão mais facilidade em estabelecer a lactação com os demais filhos ${ }^{23,28,29,31-33}$. Dados também encontrados neste estudo, no qual quase metade das mães eram primíparas. Entretanto, devido ao baixo número de mães sem experiência em amamentar, não foi possível estabelecer uma relação de significância com a avaliação da mamada.

A escolaridade materna e sua influência no aleitamento materno é fator de divergência entre os autores, alguns acreditam que a baixa escolaridade mostra relação desfavorável ao estabelecimento da lactação ${ }^{1,26,30,31,33,34}$. Entretanto, há divergências, como no estudo transversal aninhado a uma coorte, no qual foi observado que mães com menor escolaridade e menor renda iniciaram mais precocemente a amamentação ${ }^{29}$.

Volpini e Moura 22 não encontraram associação entre a escolaridade materna e a renda familiar com a amamentação, contudo, a 
literatura é controversa na medida em que alguns autores ${ }^{26,28,35}$ concordam que mulheres de baixa renda possuem menor índice de aleitamento, tendo 2,3 vezes mais chances de desmamarem seus filhos precocemente ${ }^{27}$. Todavia, em outro estudo ${ }^{36}$ foi encontrada como variável relacionada com maior possibilidade de amamentar, mães com menor renda familiar. No estudo atual, a renda familiar e escolaridade materna não estiveram associadas a um maior número de alterações da mamada, possivelmente por ser uma população na qual a maioria das participantes pertencia a nível socioeconômico e de escolaridade semelhante.

Com relação ao tipo de parto, alguns pesquisadores ${ }^{15,23,30,33}$ referem o parto cirúrgico como um fator de risco para o desmame precoce, favorecendo um maior tempo de separação mãe/recémnascido, retardando portanto, o início e também a frequência das mamadas ${ }^{28}$. Silveira e colaboradores ${ }^{29}$ realizaram um estudo transversal aninhado a uma coorte na cidade de Pelotas-RS, entrevistando 2741 mães, observando risco aproximado duas vezes maior para o desmame entre aquelas cujo parto foi cirúrgico. Por outro lado, o parto cirúrgico pode ser um fator de proteção para a amamentação, pois é dada maior atenção pela equipe às mulheres que foram submetidas à cesariana, exatamente pelo maior risco que estas possuem em apresentar dificuldade durante a amamentação ${ }^{34}$. Entretanto, na pesquisa atual não foi encontrada diferença com relação ao tipo de parto, provavelmente por se tratar de uma população que, além de ter um alto índice de parto transpelviano, teve seus filhos em uma maternidade com o título de Hospital Amigo da Criança ${ }^{26,36}$.

Poucos estudos referem a relação peso ao nascer com 0 aleitamento materno em neonatos a termo saudáveis, sendo observado apenas no estudo de Bertini e colaboradores ${ }^{31}$ uma influência negativa associada a recém-nascidos com peso insuficiente ao nascimento. No atual estudo não foi encontrada diferença associada a essa variável, ou mesmo com relação à idade gestacional.

Durante o manejo do aleitamento materno é importante que o profissional que atende ao binômio mãe/recém-nascido esteja atento à disfunção oral, pois quando presente, pode interferir no desempenho da mamada, sendo fundamental iniciar o tratamento o quanto antes. No presente estudo, observou-se que quase dois terços da população apresentaram algum tipo de alteração na mamada. Estas ocorreram em maior proporção, de acordo com o maior número de alterações do sistema sensório motor oral do neonato. Poucos trabalhos relatam a influência dessa variável tão importante no estabelecimento da lactação, porém esse fator deve ser considerado ao avaliar a mamada ${ }^{10,11,23}$.

Um dos poucos estudos que referem à associação da disfunção oral com dificuldades durante a amamentação ressalta que $13 \%$ da população estudada apresentou mamada insatisfatória, sendo esse o risco para os recém-nascidos que tiveram alterações de sucção, cerca de oito vezes maior ${ }^{16}$. É necessário enfatizar que dois quintos da população avaliada no presente estudo apresentaram de uma a duas alterações durante a avaliação da mamada, caracterizadas por movimentos orais atípicos, sendo que a maior parte delas provavelmente ocorreu devido à adaptação entre o binômio mãe/filho, no início do estabelecimento da lactação. É necessário chamar a atenção que muitas vezes esta adaptação é um processo transitório e que faz parte do aprendizado espontâneo da díade ${ }^{33}$. Contudo, na persistência desses sinais, deve-se averiguar a real dificuldade no estabelecimento da lactação e tratá-la ${ }^{16}$.

O fato de ter sido introduzida a avaliação do desempenho do sistema sensório motor oral, detalhando mais os aspectos relativos à criança, e essa avaliação ter sido realizada por um profissional especializado em identificar as alterações do sistema sensório motor oral, chama a atenção para essa variável nova que é a disfunção oral, e de sua grande importância no estabelecimento do aleitamento materno, pois apresenta uma relação diretamente proporcional às alterações da mamada.

Há autores ${ }^{7,16,24}$ que ressaltam a importância de alterações relativas ao sistema sensório motor oral (disfunções orais), pois mesmo com baixa prevalência considerando a população total, quando presentes, interferem negativamente no aleitamento materno, fazendo com que, em alguns casos, a criança venha a recusar o peito, ou não se satisfaça com o leite materno por não conseguir sugar adequadamente ${ }^{1,24}$. Afinal, a sucção é uma função complexa, necessária para a criança no período pós-natal, e a alimentação depende da coordenação dos movimentos intra-orais e do ritmo da sucção ${ }^{2}$, cabendo aos profissionais da área de saúde ajudarem as mães no período pós-parto, a fim de minimizar essas dificuldades ${ }^{1}$. Assim deve-se apoiar principalmente àquelas crianças que apresentarem um maior número de alterações do sistema sensório motor oral, considerada, neste estudo, por no mínimo três alterações dos dez aspectos avaliados.

Pode-se apontar como limitações do método deste estudo, o fato de a coleta ter sido realizada por uma única pesquisadora, não permitindo que a mesma estivesse cega ao resultado do desempenho da avaliação do sistema sensório motor oral 
quando realizou a observação da mamada, com a possibilidade de existir um viés do observador quando um resultado poderia ser sugestivo ao outro. Porém, este possível viés foi minimizado por meio do treinamento da pesquisadora e da padronização da avaliação. Além disso, o fato de ser um estudo transversal, o qual não permite relacionar às dificuldades iniciais da amamentação com o processo de manutenção do aleitamento materno exclusivo posteriormente, restringindo-se a avaliação dentro da maternidade nas primeiras 48 horas de vida do neonato.

Por outro lado, inova a metodologia de observação da amamentação, pela inclusão de itens específicos ao desempenho oral do recém-nascido, cujo mérito é ser passível de reprodução na prática assistencial, realizando avaliação precoce, devendo ser adotada como rotina nas maternidades.

\section{CONCLUSÃO}

A disfunção oral do neonato a termo saudável é um dos fatores que interfere no estabelecimento da lactação. Assim, faz-se necessária, sempre que possível, a presença de equipe capacitada no manejo do aleitamento materno, com a inclusão de profissional que dê atenção especial às alterações do sistema sensório motor oral nas maternidades, para, além de transmitir informações às mães e prevenir alterações, também tratar as eventuais interferências das disfunções orais na lactação. Esse estudo demonstrou que não há associação entre a disfunção oral e os fatores socioeconômicos, provavelmente por se tratar de uma população homogênea.
A melhoria na qualidade da assistência à saúde materno-infantil pode ser considerada uma medida de extrema importância para o aumento nos índices de aleitamento materno e, os fatores que influenciam essa prática devem ser consolidados na operacionalização destas ações. As intervenções devem, ainda, propiciar às mães oportunidades de adquirir habilidades, minimizando as dificuldades iniciais.

A partir deste estudo, sugerem-se novas pesquisas que, além de envolver formulários de observação da mamada, promovam estudos prospectivos com propostas específicas de intervenção junto às mães e aos recém-nascidos, assim como o treino oral para neonatos com desordens no desempenho funcional oral durante a amamentação, e que analisem o desempenho da mamada em diversas camadas socioeconômicas.

\section{AGRADECIMENTOS}

À Coordenação de Aperfeiçoamento de Pessoal de Nível Superior (CAPES) e ao Conselho Nacional de Desenvolvimento Científico e Tecnológico (CNPq) pelas bolsas de estudo oferecidas à mestranda Karine Dutra. Aos diretores da Maternidade Professor Bandeira Filho, Thuran Cedric César da Silva e Erick Moreno Martinez pelo apoio institucional e seus profissionais pelo apoio durante a coleta. A todas as mães e filhos que participaram do estudo. À professora Marília Lima, do departamento de Saúde da Criança e do Adolescente da UFPE, pela ajuda na análise dos dados. 


\section{ABSTRACT}

Purpose: to check the association between oral dysfunction and socioeconomic factors, variables related to the mother and to the newborn as well breastfeeding performance during the first 48 hours of life. Methods: a cross-sectional study, analytical, carried out at a public maternity of Recife (PE Brazil). All mothers of full-term newborns were attended between April and July 2008, totaling 588 mother/infant pairs. The assessment of the oral motor sensory system of the child and breastfeeding performance were developed, coded as a zero when the item was "expected / normal" and one where "not expected and risk." The total sum of the items "not expected and risk" resulted in an Index of Oral Dysfunction and an Index of Breastfeeding Performance. Results: it was found that $57.3 \%$ of the mother/infant pairs had change of feeding, $43.9 \%$ had 1 and/or 2 changes and $13.4 \%$ greater number of changes. The frequency of oral dysfunction was approximately $30 \%$. In logistic regression analysis among the included variables, just the oral dysfunction remained significantly associated with the failure of breastfeeding. Children with many changes in oral function showed a 4 times greater chance to get feeding alteration. Conclusions: oral dysfunction is one of the causes for non-establishment of lactation, and should be identified early, as it may be corrected, thereby avoiding weaning. The maternity staff should be trained in breastfeeding management, with a healthcare professional that offers special care for abnormalities in the oral motor sensory system.

KEYWORDS: Breast Feeding; Sucking Behavior; Weaning; Lactation; Infant. Newborn

\section{REFERÊNCIAS}

1. Simard I, O'Brien HT, Beaudoin A, Turcotte D, Damant D, Ferland $S$, et al. Factors influencing and duration of breastfeeding among low-income women followed by the Canadá Prenatal Nutrition Program in 4 regions of Quebec. J Hum Lact. 2005; 21(3):327-37.

2. Mizuno K. Neonatal feeding performance as a predictor of neurodevelopmental outcome at 18 months. Dev Med Child Neurol. 2005; 47:299-304.

3. Cooke M, Schmied V, Sheehan A. An exploration of the relationship between postnatal distress and maternal role attainment, breast feeding problems and breast feeding cessation in Australia. Midwifery. 2007; 23:66-76.

4. Weinstein ME, Oleske JM, Bogden JD. A selected review of breast-feeding recommendations. Nutr Res. 2006; 26:379-84.

5. Neiva FCB, Leone CR. Sucking in preterm newborns and the sucking stimulation. Pró-Fono. 2006; 18(2):141-50.

6. Castro AG, Lima MC, Aquino RR, Eickmann SH. Desenvolvimento do sistema sensório motor oral e motor global em lactentes pré-termo. Pró-Fono. 2007; 19(1):29-38.

7. Neiva FCB. Sucção em recém-nascidos: algumas contribuições da fonoaudiologia. Pediatria. 2000; 22(3):264-70.

8. Hernandez AM. Atuação fonoaudiológica com o sistema estomatognático e a função de alimentação. In Hernandez AM. O neonato. São José dos Campos: Pulso; 2003. p.47-78.

9. Araújo CMT, Silva GAP, Coutinho SB. A utilização da chupeta e o desenvolvimento sensório motor oral. Rev. CEFAC 2009; 11(2):261-7.

10. Andrade CRF, Gullo ACP. As alterações do sistema motor oral dos bebês como causa das fissuras/ rachaduras mamilares. Pediatria. 1993; 15:28-33.

11. Sanches MTC. Amamentação: enfoque fonoaudiológico. In: Carvalho MR, Tamez RN. Amamentação: bases científicas para a prática profissional. Rio de Janeiro: Guanabara Koogan; 2002. p.50-9.

12. Giugliani ERJ. Problemas comuns na lactação e seu manejo. J Pediatr. 2004; 80(5):147-54.

13. Araújo OD, Cunha AL, Lustosa LR, Nery ISN, Mendonça RCM, Campelo SMA. Aleitamento materno: fatores que levam ao desmame precoce. Rev Bras Enferm. 2008; 61(4):488-92.

14. Sanches MTC. Manejo clínico das disfunções orais na amamentação. J Pediatr. 2004; 80(5):155-62.

15. Marques MCS, Melo AM. Amamentação no alojamento conjunto. Rev. CEFAC. 2008; 10(2):261-71.

16. Sanches MTC. Dificuldades iniciais na amamentação: enfoque fonoaudiológico. [dissertação]. São Paulo (SP): Universidade de São Paulo; 2000.

17. Capurro H, Konicheszky S, Fonseca D, CaldeyroGarcia R. A simplified method for diagnosis of 
gestacional age in the newborn infant. $J$ Pediatr. 1978; 93:120-2.

18. Neiva FCB, Leone CR. Development of sucking rhythm and the influence of stimulation in premature infants. Pró-Fono. 2007; 19(3):241-8.

19. Unicef/OMS. Manejo e promoção do aleitamento materno num Hospital Amigo da Criança; um curso de 18 horas para equipes de maternidades. Brasília; 1993.

20. Shimoda GT, Silva IA, Santos JLF. Características, freqüência e fatores presentes na ocorrência de lesão de mamilos em nutrizes. Rev Bras Enferm. 2005; 58(5):529-34.

21. França MCT, Giugliani ERJ, Oliveira LD, Weigert EML, Santo LCE, Köhler CV, et al. Uso de mamadeira no primeiro mês de vida: determinantes e influência na técnica de amamentação. Rev Saúde Pública. 2008; 42(4):607-14.

22. Volpini CCA, Moura EC. Determinantes do desmame precoce no distrito noroeste de Campinas. Rev Nutr. 2005; 18(3):311-9.

23. Meirelles CAB, Oliveira MIC, Mello RR, Varela $M A B$, Fonseca VM. Justificativas para uso de suplemento em recém-nascidos de baixo risco de um Hospital Amigo da Criança. Cad. Saúde Pública. 2008; 24(9):2001-12.

24. Wallace LM, Dunn OM, Alder EM, Inch S, Hills RK, Law SM. A randomised-controlled trial in England of a postnatal midwifery intervention on breast-feeding duration. Midwifery. 2006; 22:262-73. 25. Alves CRL, Goulart EMA, Colosino EA, Goulart LMHF. Fatores de risco para o desmame entre usuárias de uma unidade básica de saúde de Belo Horizonte, Minas Gerais, Brasil, entre 1980 e 2004. Cad. Saúde Pública. 2008; 24(6):1355-67.

26. Silva MB, Albenaz EP, Mascarenhas MLW. Silveira RB. Influência do apoio à amamentação sobre o aleitamento materno exclusivo dos bebês no primeiro mês de vida e nascidos na cidade de Pelotas, Rio Grande do Sul, Brasil. Bras Saúde Matern Infant. 2008; 8(3):275-84.

27. Oliveira LPM, Assis AMO, Gomes GSS, Prado MS, Barreto ML. Duração do aleitamento materno, regime alimentar e fatores associados segundo condições de vida em Salvador, Bahia, Brasil. Cad Saúde Pública. 2005; 21(5):1519-30.

28. Faleiros FTV, Trezza EMC, Carandina L. Aleitamento materno: fatores de influência na sua decisão e duração. Rev Nutr. 2006; 19(5):623-30.

29. Silveira RB, Albernaz E, Zuccheto LM. Fatores associados ao início da amamentação em uma cidade do sul do Brasil. Rev Bras Saúde Matern Infant. 2008; 8(1):1-8.

30. Boccolini CS, Carvalho ML, Oliveira MIC, Leal MC, Carvalho MS. Fatores que interferem no tempo entre o nascimento e a primeira mamada. Cad Saúde Pública. 2008; 24(11):2681-94.

31. Bertini G, Perugi S, Dani C, Pezzani M, Tronchin M, Rubaltelli FF. Maternal education and the incidence and duration of breast feeding: a prospective study. J Pediatr Gastroenterol Nutr. 2003; 37:447-52.

32. Bystrova K, Widström AM, Matthiesen AS, Arvidson ABR, Nyström BW, Vorontsov I, et al. Early lactation performance in primiparous and multiparous women in relation to different maternity home practices. A randomized trial in St. Petersburg. Int Breastfeed J. 2007; 2(9):1-14.

33. Bakoula C, Nicolaidou P, Veltsista A, Prezerakou A, Moustaki M, Kavadias G, et al. Does exclusive breastfeeding increase after hospital discharge? A Greek study. J Hum Lact. 2007; 23(2):165-73.

34. Bittencourt LJ, Oliveira JS, Figueiroa JN, Batista Filho M. Aleitamento materno no estado de Pernambuco: prevalência e possível papel das ações de saúde. Rev Bras Saúde Matern Infant. 2005; 5(4):439-48.

35. Mascarenhas ML, Albenaz EP, Silva MB, Silveira RB. Prevalence of exclusive breastfeeding and its determiners in the first 3 months of life in the South of Brazil. J Pediatr. 2006; 82(4):289-94.

36. Ramos CV, Almeida JAG, Alberto NSMC, Teles JBM, Saldiva SRDMS. Diagnóstico da situação do aleitamento materno no Estado do Piauí, Brasil. Cad. Saúde Pública. 2008; 24(8):1753-62.

RECEBIDO EM: 24/09/2009

ACEITO EM: 27/02/2010

Endereço para correspondência:

Karine Dutra Valério

Rua Professor Waldemar de Oliveira, 65/602

Recife - PE

CEP: 51021-240

E-mail: karinedutra@yahoo.com.br 